Revue

Revue de l'histoire des religions

de Ihistoire des religions

\title{
La satire de la Révélation dans le Cymbalum mundi
}

Satire of the Revelation in the Cymbalum mundi

\section{Alain Mothu}

\section{OpenEdition}

\section{Journals}

Édition électronique

URL : http://journals.openedition.org/rhr/8755

DOI : $10.4000 /$ rhr.8755

ISSN : 2105-2573

Éditeur

Armand Colin

Édition imprimée

Date de publication : 1 septembre 2017

Pagination : 457-483

ISBN : 978-2-200-93127-8

ISSN : 0035-1423

\section{Référence électronique}

Alain Mothu, «La satire de la Révélation dans le Cymbalum mundi », Revue de l'histoire des religions [En ligne], 3 | 2017, mis en ligne le 01 septembre 2019, consulté le 06 janvier 2021. URL : http:// journals.openedition.org/rhr/8755; DOI : https://doi.org/10.4000/rhr.8755 


\section{La satire de la Révélation dans le Cymbalum mundi}

Publié à la fin de 1537 ou au tout début de 1538, le Cymbalum Mundi, petit livre français contenant «quatre dialogues poétiques, fort antiques, joyeux et facétieux », fut jugé pernicieux, impie et détestable par tous les contemporains, tant catholiques que protestants, et tôt supprimé par les autorités. Dans cet article, nous souhaitons montrer qu'ils ne se trompaient pas: l'auteur, Bonaventure Des Périers, plantait le glaive au cour de la Révélation chrétienne, en se moquant notamment de la "Bonne Nouvelle» et du Verbe divin. Le Cymbalum représente donc un indéniable témoignage antichrétien, philosophiquement très mûr, du premier $X^{e} I^{e}$ siècle et, comme tel, il se pose sûrement comme un document de première importance pour l'histoire religieuse de l'Europe moderne.

\section{Satire of the Revelation in the Cymbalum mundi}

Published at the end of 1537 or at the very beginning of 1538, the Cymbalum Mundi, a small French book containing "four poetic, very ancient, joyful and facetious dialogues", was considered pernicious, godless and hateful by all contemporaries, Catholics as well as Protestants, and was soon suppressed by the authorities. This paper attempts to show that they were not mistaken : the author, Bonaventure Des Périers, thrusts his sword into the heart of Christian Revelation by mocking the Good News and the divine Word in particular. The Cymbalum thus represents an undeniably anti-Christian testimony, philosophically very mature, from the early $16^{\text {th }}$ century and, as such, it certainly takes its place as a document of great importance for the religious history of Modern Europe. 


\section{«Pernicieux »?}

« Pernicieux et donc à supprimer » (perniciosus est, ideo supprimendus) : ainsi se concluait, le 19 juillet 1538, le jugement de la Faculté de théologie de l'université de Paris concernant le Cymbalum mundi, petit ouvrage d'apparence pourtant fort innocente, puisque bâti de « quatre Dialogues Poetiques, fort antiques, joyeux, et facetieux », publié à Paris peut-être à l'extrême fin de 1537 (date de publication affichée), avant d'être réédité à Lyon l'année suivante $^{1}$. Quelques mois avant que la Sorbonne ne se prononçât, début mars 1538, le chancelier Antoine du Bourg, armé d'une lettre royale et d'un exemplaire du libelle, avait saisi à son sujet le Parlement de Paris, en la personne de son premier président Pierre Lizet : au dire de François ${ }^{\mathrm{er}}$ en personne, le Cymbalum abriterait en effet de «grands abuz et heresies » éminemment punissables. Chasse devait donc être donnée à son « compositeur», autrement dit son auteur, et son «imprimeur $»^{2}$.

1. Registre des conclusions de la Faculté de théologie de l'Université de Paris, t. II : du 26 novembre 1533 au $1^{\text {er }}$ mars 1550, éd. James K. Farge, Paris, Klincksieck, 1994, p. 130. Dans les années 1530, de nombreux imprimeurs parisiens adoptent le «nouveau style» romain fixant le début de l'année aux calendes de janvier, à la différence de l' «ancien style» gallican, ou «style de Pâques ». Néanmoins cet usage reste globalement fluctuant. Dans la suite de l'article, nous citerons le Cymbalum mundi, ou CM, d'après les deux éditions de Peter H. Nurse (Genève, Droz, 1957, rééd. 1983) et de Max Gauna (Paris, Champion, 2000), le chiffre romain après $C M$ indiquant le numéro du dialogue. Nous avons développé plusieurs points abordés ici dans une série d'articles publiés, notamment, dans la Bibliothèque d'Humanisme et Renaissance (= BHR), entre 2012 et 2016. Nous n'y renverrons qu'occasionnellement.

2. Lizet reçut le 5 mars le paquet contenant la lettre du roi paraphée du chancelier ou accompagnée d'une lettre du chancelier et le $C M$, et il en référa à l'Assemblée le 7. L'étude la plus substantielle concernant la publication et la censure du $C M$ reste celle de Lucien Febvre, "Une histoire obscure : la publication du $C M$ », Revue du seizième siècle, XVII, 1930, p. 1-41. Ajoutons-y Michel Simonin, «Vol au-dessus d'un nid de corbeaux : le prince, les lettres et le $C M$ », Le Cymbalum mundi [Actes du colloque de Rome, 2000], éd. Fr. Giacone, Genève, Droz, 2003, p. 43-56. Nous ne partageons cependant pas son avis (p. 44) suivant lequel le compositeur serait l'imprimeur et l'imprimeur forcément le libraire. Le premier est l'auteur dans tous les cas cités par Huguet dans son Dictionnaire, mais il pouvait désigner aussi la personne qui avait établi le texte sur la forme d'imprimerie à partir d'un manuscrit. Quant au second, il désignait ordinairement l'imprimeur réel 
Par quel canal le roi, alors présent à Moulins pour célébrer l'accession de Montmorency au rang de connétable de France, avait-il été avisé de la parution de l'opuscule ? Un familier ou un fonctionnaire zélé était-il tombé dessus par hasard et lui avait-il fait valoir que cette publication contrevenait gravement à sa dernière ordonnance en matière de librairie, obligeant tout professionnel à soumettre au préalable à la Bibliothèque du roi un exemplaire de chaque publication à des fins de contrôle idéologique et de préservation culturelle ${ }^{3}$ ? Doit-on plutôt envisager une dénonciation intéressée par un ennemi personnel de l'auteur, à rechercher par exemple dans le parti réformateur, sinon dans quelque faction politico-littéraire adverse, ou encore dans le milieu de la librairie lyonnaise ${ }^{4}$ ? La question reste controversée. Ce qui est certain, c'est que le «compositeur», Bonaventure Des Périers (l'attribution, parfois contestée, est hors de doute) ${ }^{5}$, ne fut jamais officiellement inquiété ni même nommé lors de la procédure : on suppose ordinairement que sa condition de «valet de chambre » de Marguerite de Navarre, sœur du roi, et peut-être aussi son éloignement de Paris au moment de l'affaire, suffirent à sa protection.

Car son identité avait bel et bien été livrée par l'éditeur du Cymbalum, Jehan Morin, «pauvre jeune garson, libraire de Paris »

et parfois le libraire ou éditeur qui avait donné l'ouvrage à imprimer : c'était le cas de Morin, qui ne possédait pas de presses (le colophon du CM le déclare « imprimé nouvellement à Paris pour Jehan Morin »). Prévenons que la réédition lyonnaise du $C M$ datée de 1538, par Benoist Bonnyn, échappa à l'attention des magistrats ; elle n'échappera cependant pas à la suppression.

3. Ordonnance de Montpellier, 28 décembre 1537, enregistrée au Châtelet le 7 mars 1538. Voir Magali Vène, «L'Ordonnance de Montpellier» sur http:// expositions.bnf.fr/francoisIer/arret/06-4.htm James Knox Farge mettait en avant un argument de cette nature dans son édition du Registre des conclusions de la Faculté de théologie, t. II : Du 26 novembre 1533 au $1^{\text {er }}$ mars 1550, Paris, Klincksieck, 1994, p. 131, n. 22, mais il s'appuyait sur des ordonnances, soit trop ancienne (celle de janvier 1535, consécutive à l'affaire des Placards), soit postérieures au $C M$.

4. Religieux: Des Périers avait récemment rompu avec la Réforme (1535-1536). Politico-littéraire : il avait ardemment pris la défense de Marot contre le poète François de Sagon et son clan (1535-1537). Librairie lyonnaise : Étienne Dolet aurait voulu complaire au roi, qui lui décerna en mars 1538 un privilège général d'imprimeur pour dix ans, en dénonçant son ancien collaborateur (hypothèse récemment développée par Jean-François Vallée, «Le corbeau et la cymbale. Étienne Dolet et le $C M », B H R$, LXVII-1, 2005, p. 121-135).

5. Voir notre article, «L'attribution du $C M$ et le "mystère" Des Périers ", La Lettre clandestine, 23 (2015), p. 227-247. 
qui n'eut pas la même bonne fortune que l'auteur ${ }^{6}$. Lui ne tarda pas à être identifié et mis aux fers, puisqu'il avait affiché ses marque, nom et adresse sur l'ouvrage. En même temps, ces indications attestaient l'innocence de ses intentions. Cependant, ses activités n'étant pas transparentes à tous égards (on trouva notamment chez lui des livres «venans d'Allemagne »), il fut condamné à la confiscation de ses biens et à l'exil par une sentence rendue par la prévôté de Paris (le Châtelet) en mai ou début juin, le Cymbalum étant de son côté déclaré contenir "aulcun[e]s [scil. quelques] erreurs et paroles scandaleuses contre la foy catholique » et mériter les flammes. Morin fit appel de cette sentence auprès du Parlement et cette cour se tourna alors vers la Sorbonne (fin juin) pour savoir si le livre que l'accusé avait voulu répandre comportait réellement «aulcun[e] s erreurs et heresies ». Ainsi en arrivonsnous à la conclusion partiellement citée au début de cet article, tirée par les quatre examinateurs désignés par le doyen Dominique Le Cirier : « conclusum fuit quod, quamvis liber ille non contineat errores expressos in fide, tamen quia perniciosus est, ideo supprimendus $\gg^{7}$.

On n'entendit, semble-t-il, plus parler de Jehan Morin, exilé ou plus vraisemblablement mort en prison, puisqu'un acte le décrit comme très malade; nous n'avons sur ce point aucune certitude ${ }^{8}$. Quant à ce « povre Dedalus » de Des Périers - ainsi qu'il se nomme

6. Comme il s'appelle lui-même dans une requête non datée (antérieure au 16 avril 1538) au Chancelier Du Bourg, dont une copie manuscrite - attribuée à Claude Dupuy, le père de Pierre et Jacques - est jointe à l'exemplaire de l'édition lyonnaise de 1538 (éd. B. Bonnyn) conservé à la BnF (Rés Z-2442, consultable sur Gallica).

7. Registre des conclusions de la Faculté de théologie, éd. Farge, p. 130. Les noms des quatre examinateurs sont donnés : Nicolas Le Clerc, prieur de Sorbonne ; Nicolas de Grambus, curé parisien; Jean Bertoul, recteur de l'Université ; le dominicain Thomas Laurent.

8. Pas même celle qu'il ne fut pas finalement relaxé, comme pourrait le suggérer un Manuel d' «Epictetus» signalé par Philippe Renouard dans son Inventaire chronologique des éditions parisiennes du XVI siècle (éd. du Service des travaux historiques de la Ville de Paris, t. v : 1536-1540, Abbeville, ParisMusées / Paillart, 2004, p. 268, n 849), visible sur le site de la BSB de Munich (Rar. 812). Quoique dénué de toute adresse ou marque de libraire, le livre est en effet doté d'un privilège accordé par De Mesmes à «Jehan Morin Libraire en l'université de Paris » le 3 janvier 1538, donc peut-être 1539, puisqu'une majorité d'actes administratifs conservaient alors le style de Pâques; mais était-ce systématique et un parent n'a-t-il pu se substituer à lui ? Il faudrait étudier ce cas plus attentivement. 
lui-même dans une épître à Marguerite de Valois, fille du roi ${ }^{9}$ une légende diffuse relate qu'une sourde disgrâce s'abattit sur lui et lui broya les ailes, tant à la cour de Navarre qu'au sein de la sodalitas lugdunensis, qui se conclut par un suicide vers $1543^{10}$. Mais nous parlons bien de légende : il se peut que la reine passât l'éponge et que ce fût une maladie qui lui gangréna les ailes. Reste «Bonaventure qu'enveloppe un silence si total, si mystérieux, si vraiment anormal », comme disait Lucien Febvre ${ }^{11}$, soit l'étrange omerta qui entoura durablement son nom parmi les humanistes et poètes lyonnais contemporains : on peut croire que l'impression du Cymbalum n'y fut pas étrangère. Un tabou majeur avait peut-être été enfreint.

Ce fut, à notre avis, l'opinion même des théologiens de la Sorbonne. Il est vrai que de nombreux exégètes modernes ont perçu dans leur verdict et spécialement dans l'emploi du mot «pernicieux » une sorte de condamnation par défaut, un lâche démenti du jugement de François I $^{\text {er }}$ - ou de son cercle - faisant une concession obligée et seulement formelle à l'irréfragable intuition royale. Francis Higman a ainsi estimé qu'en opposant au roi l'idée d'un livre condamnable parce que pernicieux, la Sorbonne s'exprimait dans les termes les plus faibles possibles et que cela trahissait un sérieux recul de l'autorité qu'elle s'était récemment acquise $^{12}$. C'est selon nous inexact. Même si l'appréciation exigeait

9. «Epistre à Madame Marguerite fille du Roy», Recueil des ceuvres de feu Bonaventure Des Periers, Vallet de chambre de Treschestienne Princesse Marguerite de France, Royne de Navarre, Lyon, Jean de Tournes, 1544, p. 77 [Euvres, I, éd. Lacour, 1856, p. 72]. Des Périers se dit Dedalus dans plusieurs autres pièces. Dédale, homme aux malheurs multiples (cf. Xénophon, Mém. IV), fut notamment emprisonné dans l'antre même qu'il avait bâti. Doit-on y voir un symbole de la situation de Des Périers, retenu à la cour de Navarre après la publication de son $C M$ ?

10. L'hypothèse d'une disgrâce même provisoire de Des Périers auprès de la reine de Navarre est controversée, comme celle de son suicide (affirmation d'Henri Estienne, 1566). En revanche, le silence entourant son nom à Lyon - lui qui fut collaborateur d'Olivétan en 1535, de Dolet en 1536, défenseur de Marot en 1536-1537, poète attaché à Marguerite, etc. -, a intrigué beaucoup de critiques.

11. L. Febvre, Le Problème de l'incroyance au Xvie siècle [1942], Paris, Albin Michel, 2003, p. 94.

12. F. M. Higman, Censorship and the Sorbonne. A bibliographical study of books in French censured by the Faculty of theology of the University of Paris, 1520-1551, Genève, Droz, 1979, p. 35 («the weakest terms it ever used»). Febvre, de même, parle d'une «appréciation relativement modérée » («Une histoire obscure...», art. cit., p. 12). 
a priori un minimum de doigté diplomatique, et même si le livre était condamné d'avance, le roi ayant initié et préjugé l'affaire, force est de constater que «pernicieux », à l'époque, n'était en rien un terme faible. Il signalait un danger bien réel, quelque chose de nocif - pernicies est la destruction, la ruine, ou le fléau qui la cause -, mais perversement dissimulé. Or il n'est ni toujours facile, ni toujours souhaitable, d'éventer ce qui est dangereux.

Il faut bien comprendre, premièrement, que la Faculté de théologie n'était en principe compétente que pour apprécier l'orthodoxie dogmatique de propositions théologiques (expresses, insinuées ou immédiatement déductibles), ou éventuellement pour juger de la rectitude morale d'un texte ou d'un propos - soit sa conformité avec la bonne doctrine. Cependant il n'y avait rien de tel, aucune erreur doctrinale à dénoncer dans le Cymbalum. L'opuscule n'était pas hérétique, il ne soutenait aucune position « expresse », n'affirmait ni n'infirmait proprement rien dans l'ordre théorique, mais transposait tout son propos dans la fiction décalée d'une farce littéraire à l'antique où les équivoques étaient reines, les insinuations foisonnantes (généralement assorties de leurs apparents démentis), les écueils et les diversions redoutables. Les théologiens, qui n'étaient pas les ânes que certains ont dit, ont certainement bien perçu de quoi il retournait dans ces quatre dialogues prétendument joyeux et facétieux que « Thomas Du Clevier» adressait «à son amy Pierre Tryocan ${ }^{13}$, mais necessitas probandi incumbit ei qui agit, et l'ingénieuse stratégie de brouillage qu'y déployait l'auteur les rendait bien difficiles à « corriger».

En outre, leur satire portait bien au-delà ou, si l'on préfère, bien en amont de ce qui était à l'ordre théologique du jour : l'ouvrage s'en prenait, non pas à tel ou tel élément de la foi chrétienne, mais à son socle même, comme l'ont noté bien avant nous, à propos justement du jugement de la Faculté, Alfred Cartier et Abel Lefranc, et comme nous pourrons le vérifier ici une nouvelle fois ${ }^{14}$. Or, on tend aujourd'hui à oublier ce vieux constat d'Henri

13. Les anagrammes «Thomas incrédule " (à une coquille près) et «Pierre croyant » ne seront « officiellement » déchiffrées qu' au XIX ${ }^{\mathrm{e}}$ siècle (Élie Johanneau, 1829), cependant il est loisible de se demander si vraiment personne ne s'aperçut de rien en un $\mathrm{XVI}^{\mathrm{e}}$ siècle rompu aux énigmes, rébus, jeux de lettres et de mots, d'autant que les prénoms apostoliques de Thomas et Pierre mettaient sur la piste.

14. A. Cartier, «Le libraire Jean Morin et le $C M$ de Bonaventure des Périers devant le Parlement de Paris et la Sorbonne », Bulletin historique et littéraire de la Société de l'histoire du Protestantisme français, XxxvIII, 1889, p. 575-588, ici 
Weber suivant lequel, avant le développement de la ContreRéforme, l'Église romaine est avant tout soucieuse de «défendre ses privilèges et de pourfendre l'hérésie » et largement indifférente à «toutes les formes de l'épicurisme» et aux «spéculations philosophiques » qui lui paraissaient «entièrement étrangères aux points essentiels de la théologie réformée $»^{15}$. Ces positions - globalement mal définies - ne semblaient pas, en 1538, représenter un danger véritable. Qui plus est, les plus irréligieuses d'entre elles étaient a priori intellectuellement et moralement disqualifiées en raison de leur folie ou de leur monstruosité supposée (l'atheus est classiquement insipiens et monstrum). Résolument excentriques, n'ayant aucun droit de cité dans la respublica christiana, elles étaient supposées ne pas devoir exister et comme telles devaient être tues - étouffées sous le silence comme l'on tait un péché nefandum ${ }^{16}$.

L'adjectif «pernicieux», sans plus de précision (ce qui est rare, sinon unique, dans les arrêts de la Sorbonne) $)^{17}$, pouvait être un nom pour un silence de cette nature. Non seulement il était pratiquement impossible de «corriger» l'insinuant Cymbalum, mais déclarer les raisons précises pour lesquelles ce texte était dangereux serait revenu, ni plus ni moins, à donner corps et vie à ce qui jusqu'alors n'existait que virtuellement et, partant, à consacrer la victoire d'un auteur qui n'avait jamais attendu autre chose de ses lecteurs - à savoir que chacun parcoure pour lui-même ce chemin d'actualisation de l'implicite. Il n'en était pas question.

p. 582 ; A. Lefranc, « Rabelais et les Estienne. Le procès du $C M$ de Bonaventure Des Périers », Revue du seizième siècle, xv, 1928, p. 356-366, ici p. 363 ; voir encore Henri Hauser, Études sur la Réforme française, Paris, Picard, 1909, p. 56.

15. H. Weber, «Éléments de rupture entre la Renaissance et la Réforme en France » [1976], À travers le XVI siècle, Paris, Nizet, 1986, t. II, p. 7-29, ici p. 17 ; et notre article, «Le Livre de Jupiter. L'athéologie du CM », BHR, LXXviII-2, 2016, p. 333-361, ici p. 338 et la conclusion, p. 360-361.

16. La catégorie du nefas, d'où proviennent nefandum, nefarius, nefastus, etc. (ce qui est contraire à toute loi divine), fut régulièrement employée par les annalistes, polémistes et hérésiologues médiévaux ou plus modernes, pour nommer ce qui était proprement innommable. Voir Jacques Chiffoleau, «Dire l'indicible. Remarques sur la catégorie du nefandum du XII ${ }^{\mathrm{e}}$ au XV $\mathrm{XV}^{\mathrm{e}}$ siècle », Annales ÉSC, XLV-2, 1990, p. 289-324, spéc. p. 295.

17. Les condamnations touchant, par exemple, les «pernicieux» Colloques ou Enchiridion d'Érasme, Les Arrestz et ordonnances de la cour celeste ou encore tel manuscrit non identifié, sont toutes motivées au moins sommairement (Registre des conclusions, éd. Farge, p. 163-164 et $412 ; 182 ; 320)$. 
Notons qu'il n'en fut pas davantage question pour les rares autres contemporains qui eurent accès à l'ouvrage (malgré ses précoces suppression et interdiction) et eurent l'occasion d'en dire quelque chose qui nous soit aujourd'hui conservé. Unanimes pour le condamner, et cela de quelque parti religieux qu'ils fussent, ils se gardèrent bien de motiver leur rejet et s'en tinrent précautionneusement à l'invective haineuse. "L'aucteur Bonaventure des Periers homme meschant et athée comme il appert par ce detestable livre », écrit Louis de L'Estoile (le père de Pierre), jeune conseiller au Parlement en 1537, sur l'exemplaire de l'édition de 1538 aujourd'hui conservé à la Bibliothèque nationale de France ${ }^{18}$; «Telle vie, telle fin. Avéré par la mort de ce miserable indigne de porter le nom d'homme ", ajoutera bientôt une autre main sur le même exemplaire imprimé, en faisant allusion au suicide présumé de l'auteur ; «France est par grans espritz tirée à l'enseigne de Epicure et [...] celluy qui a faict Cymbalum Mundi ne tendit jamais à aultre chose », écrit pour sa part le protestant André Zébédée dans une lettre du 31 juillet $1538^{19}$; le Cymbalum Mundi « est d'un lucianisme qui mérite d'estre jetté au feu, avec l'autheur, s'il estoit vivant », écrira Étienne Pasquier ${ }^{20}$. Et ainsi de suite : Visagier, puis Postel, Calvin, Estienne, Chassanion et d'autres, ne se montreront pas plus prolixes en détails au sujet de notre opuscule et du vilain «singe de Lucien» qui l'écrivit ${ }^{21}$.

Aucun doute, par conséquent : «pernicieux », sans plus de détails, était le mot juste et les Magistri Nostri de la Sorbonne ne pouvaient que recommander l'élimination discrète du libelle, sans autre forme de procès : conseiller de «l'accabler sous le silence $\&$ sous

18. BnF, Rés Z-2442. L'exemplaire est paraphé «Delestoille» et l'écriture de Louis, mort en 1559, est authentifiée par Florence Greffe et José Lothe dans $L a$ Vie, les livres et les lectures de Pierre de L'Estoile. Nouvelles recherches, Paris, Champion, 2004, p. 170-171, 186, 548. Quelques pages plus loin, c'est le même qui semble avoir écrit : «dixit insipiens in corde suo non est Deus ».

19. Lettre citée par Gabrielle Berthoud, "Lettres de réformés saisies à Lyon en août 1538 », Revue de théologie et de philosophie, 24, 1936, p. 154-178, ici p. 177.

20. Étienne Pasquier, lettre à Tabourot, dans Les Lettres d'Estienne Pasquier, Paris, L'Angelier, 1586, liv. VIII, p. 246 ${ }^{\mathrm{r}}$; ou Thresor d'histoires admirables et memorables de nostre temps, Paris, Marceau, 1610, p. 106.

21. Les témoignages concernant le $C M$ ou son auteur ont été utilement recueillis par Lionello Sozzi, Les Contes de Bonaventure des Périers, Torino, G. Giappichelli, 1965, p. 55 sq. 
les horreurs d'une éternelle nuit», comme dira Adrien Baillet ${ }^{22}$. La recette était ancienne et elle avait fait ses preuves: c'est de cette manière, qui réjouissait tant Audebert Maceré, le traducteur de Tertullien, que disparurent la totalité des «escrits des anciens heretiques, schismatiques et rebelles [à l'enseignement chrétien], sinon dedans les livres des Catholiques, avec leur sentence de condemnation $»^{23}$. Toutes éradications nées du « "vandalisme" de la Chrétienté médiévale », comme disait Jacques Le Goff, qui ont fait germer la croyance historiographique saugrenue en un unanimisme chrétien prémoderne ${ }^{24}$. Or c'est de la même façon que faillit également disparaître, en 1538, le Cymbalum mundi, qui fut réputé perdu par presque tous les historiens et bibliographes jusqu'au début du XVIII ${ }^{\mathrm{e}}$ siècle. On n'en possède plus aujourd'hui qu'un unicum de l'édition de 1537, «imprimé[e] nouvellement à Paris pour Jehan Morin », et deux exemplaires de l'édition lyonnaise de 1538, «Imprimé[e] nouvellement à Lyon par Benoist Bonnyn ».

Nouvellement, lisons-nous?

\section{La Bonne Nouvelle}

Dieu tout humain d'allure et de manières, puisque aussi bien il boit et jure comme un charretier, Mercure descend sur terre pour accomplir une mission diligentée par son père, le grand Jupiter : dès les premières lignes du Cymbalum mundi, et avant même que l'on prenne la peine de s'interroger sur le sens de la mission qui

22. Adrien Baillet, Jugemens des savans sur les principaux ouvrages des auteurs, Paris, Antoine Dezallier et Amsterdam, Wolfgang, t. IV-3, 1686, p. 251 : cette sorte de damnatio memoriae est en effet la «punition la plus humiliante pour un méchant livre, \& en même tems la plus utile pour les Fidelles ».

23. Audebert Macéré, Dédicace au cardinal Charles de Lorraine, dans Tertullien, Défenses contre les heretiques, Paris, Vascoran, 1562, cité par Pierre Petitmengin, "Les Haeretici nostri temporis confrontés aux hérésies de l'Antiquité ", L'Argument hérésiologique, l'Église ancienne et les Réformes, XvI $X V I I^{e}$ s., dir. Irena Backus, Philippe Büttgen, Bernard Pouderon, Paris, Beauchesne, 2012, p. 177-198, ici p. 181. On verra sur le sujet Luca Bianchi, Censure et liberté intellectuelle à l'Université de Paris (XIII -XIV ${ }^{e}$ s.), Paris, Les Belles Lettres, 1999, introduction et $1^{\text {re }}$ part., chap. I, 1.

24. La Civilisation de l'Occident médiéval [1964], Paris, Flammarion, 1982, p. 144. Voir avant tout Ramsay MacMullen, Christianisme et paganisme du Iv au VIII ${ }^{e}$ siècle, Paris, Perrin, 2011 [e. o. 1996] ; et en amont, bien sûr, Ex 34, 14 : « mais vous demolirez leurs autelz, et desromprez leurs images... » (trad. Olivétan). 
lui a été confiée, qui est de faire relier à neuf le vieux livre de ses secrets paternels (ce qu'il faisait avant de créer le monde; ce que l'avenir nous réserve; quels seront les bienheureux élus), cette entrée en scène était bien de nature à intriguer le lecteur et elle ne manqua pas de le faire. En rapportant la théophanie à certaines anticipations écrites, les réactions ébahies des premiers témoins de l'événement ne pouvaient évidemment qu'accentuer l'impression de «déjà lu »: "Je voy maintenant ce que j'ay tant de foys trouvé en escript et que je ne pouvois croire», souffle un certain Curtalius ; "Pardieu! voyla ung homme acoustré de la sorte que les poetes nous descripvent Mercure. Je ne sçay que faire de croyre que ce le soit », lâche à son tour Byrphanès ${ }^{25}$. Cependant, nous l'avons dit, en pareille matière il n'était pas forcément du meilleur aloi de préciser ses soupçons. Mersenne, qui put lire l'ouvrage dans le cabinet des frères Dupuy, et souligna notamment la nocivité de « la fable de Mercure descendant du ciel », ne se montra guère plus explicite à son sujet que les théologiens et controversistes du siècle précédent ${ }^{26}$.

En parcourant le Cymbalum, le lecteur se verra conforté dans son impression à maintes occasions. Par exemple quand il lira, au deuxième dialogue, que Mercure, «filz de Jupiter troys fois » (scil. triple $)^{27}$, « veult que nous entr'aymions l'ung l'aultre comme

25. $C M$ I, Nurse 6, Gauna 60. L'allusion aux prophéties vétérotestamentaires paraît d'autant moins douteuse que les deux personnages désignent clairement des chrétiens, en l'occurrence des catholiques intransigeants, qui chasseront bientôt Mercure de l'auberge (comme Jésus le fut de Nazareth ? cf. Lc 4, 29) au motif qu'il «blasphem(ait) » au sujet du «nectar de Jupiter », doutant de sa qualité (soit, de la valeur de l'eucharistie).

26. «Fabellam Mercurii ex coelo descendentis »: Quaestiones celeberrimae in Genesim (Paris, Sébastien Cramoisy, 1623), version originale du colophon supprimé, Primae quaestionis adversus atheos [...], in quo atheismi expugnandi modus affertur, col. 669 sq., reproduit dans la Bibliothèque Britannique, XVIII2, 1742, ici p. 416 ; et par J. G. Chaufepié, Nouveau Dictionnaire historique et critique..., III, Amsterdam, Z. Chatelain, et alii, 1743, s.n. «Mersenne », ici p. 81 , c. 1. Mersenne a lu l'ouvrage, puisqu'il le décrit précisément et cite même (Bibl. brit., p. 410 ; Chaufepié, p. 80, c. 1) les remarques manuscrites de Louis de L'Estoile inscrites sur l'exemplaire aujourd'hui conservé à la BnF, Rés. Z-2442 ( $2^{\mathrm{e}}$ éd. de Lyon, Bonnyn, 1538). Pierre et Jacques Dupuy avaient hérité de la bibliothèque de leur père Claude, qui possédait un $C M$ de 1538 (voir supra, n. 6).

27. $C M$ II, Nurse 12, Gauna 67. L'équivoque est riche, pouvant se référer à la légende médiévale des trois Hermès, à Mercurius triplex, ou termaximus, ou Trismégiste (scil. trois fois très grand), mais également, si c'est Jupiter que l'on multiplie « troys fois », au Dieu trinitaire. 
freres $»^{28}$, ou quand il verra ailleurs le dieu trahir sa double nature humaine et divine. À la fin du premier dialogue, en effet, nous voyons ce bon et jovial personnage qu'est encore Mercure se muer d'un coup en personnage colérique et vengeur, parce que l'hôtesse d'une auberge qu'il souhaite récompenser de ses bons services en lui accordant une vie prolongée «de cinquante ans, en bonne santé et joyeuse liberté », refuse de croire à ses « riches promesses ${ }^{29}$. Comment ne pas deviner la résurgence du Dieu de justice et de colère derrière l'homme Jésus ? Une allusion semblable se profile au dialogue suivant où, ne voulant être reconnu, Mercure se transforme cette fois physiquement, comme par magie, de «beau jeune gars » en « ung viellart tout gris $»^{30}$. «Qui me voist, il voit mon père », «je suis en mon pere, et mon pere est en moy », lisait-on chez Jean (14, 5-11), que nous citons dans la traduction de Pierre Robert Olivétan à laquelle Des Périers participa entre 1534 et 1535 .

Cependant il y a plus marquant encore: le thème de la nouveauté ou des nouvelles attendues ou portées est très prégnant dans l'ensemble du Cymbalum, et il surgit notamment sitôt qu'il est question de Mercure. «Quelles nouvelles?», lui demande-t-on à plusieurs reprises ${ }^{31}$; et si lui s'enquiert de savoir « que dit-on de nouveau ?», on lui répond : « Nous n'en sçavons rien, Monsieur, si nous n'en apprenons de vous $»^{32}$. Au Ciel même, on le regarde essentiellement comme un pourvoyeur de «nouvelles $»^{33}$. C'est au point que Mercure finit par s'exaspérer du procédé : « N'est-ce pas pitié ? Soit que je vienne en terre ou que je retourne aux cieulx,

28. $C M$ II, Nurse 16, Gauna 71. Commandement d'aimer son prochain comme Jésus nous a aimés : Jn 13, $34 ; 15,12$; ou comme soi-même : Mt 22, 39 ; Mc 12, 31 ; etc. (nombreuses occurrences). Ce sont surtout Paul et Pierre qui parlent d'amour fraternel ( $\left.\varphi \imath \lambda \alpha \delta \varepsilon \lambda \varphi i^{\alpha} \alpha\right)$ : Rm 2, $10 ; 1$ Th 4, 9; He 13, 1 ; 1 Pi 1 , $22 ; 3,8 ; 2$ Pi 1,7 .

29. $C M$ I, Nurse 10, Gauna 64. Mercure se fait subitement menaçant: « [vous] serez tout le temps de vostre vie en servitude et malade toutes les lunes jusques au sang » : pastiche de Gn 3, 16 (enfantement dans la douleur, servitude envers le mari ; or, les règles féminines étaient traditionnellement conçues comme dérivant de la condamnation d'Ève à enfanter dans la douleur). La rencontre fait évidemment penser à l'épisode de la Samaritaine : Jn 4, 4-29.

30. $C M$ II, Nurse 15 , Gauna 70 .

31. $C M$ I et III, Nurse 6 et 30, Gauna 60 et 85 .

32. $C M$ I, Nurse 8 , Gauna 62.

33. CM III, Nurse 25-26, Gauna 81-82 : rapporter les Cent nouvelles nouvelles, les « nouvelles » lamentations nocturnes des vestales et les « chansons nouvelles ». 
tousjours le monde et les dieux me demandent si j'ay, ou si je sçay, rien de nouveau. Il fauldroit une mer de nouvelles, pour leur en pescher tous les jours de fresches $»^{34}$. Quoi de plus normal, se dirat-on, s'agissant du dieu gréco-romain: messager de l'Olympe, dieu de la communication, médiateur entre les mondes, etc. ? C'est effectivement ce que Des Périers aurait argué si quelque censeur sourcilleux avait entrepris de le titiller sur ce point. Du reste, plusieurs allusions au rôle de Mercure comme facteur céleste au service des olympiens, au début du troisième dialogue notamment, ainsi qu'au retentissement proprement médiatique que peuvent avoir les «nouvelles » curieuses, à la fin des troisième et quatrième dialogues, pouvaient opportunément appuyer ce plaidoyer ${ }^{35}$.

Cependant «nouvelle» est un terme éminemment équivoque - dont Érasme, entre mille autres, sut jouer ${ }^{36}$ - et la lecture incolore dont nous venons de faire état était en l'occurrence bien suspecte d'en dissimuler une autre, plus retorse, suivant laquelle Mercure est aussi et surtout le héraut d'une religion qui, dès l'origine, s'annonçait comme nouvelle - voire grosse de «toute nouveauté », comme dit Irénée ${ }^{37}$ - et plus encore, qu'il est le porteur de la

34. $C M$ III, Nurse 30 , Gauna 85.

35. Messager mythologique : $C M$ III, Nurse 24-27 ; Gauna 80-82 ; nouvelles curieuses : $C M$ III et IV ; Nurse 33, 43; Gauna 88, 98. La Prognostication des prognostications de Des Périers, publiée en 1537 quelques mois avant le $C M$, présente déjà une vive critique - selon nous ambiguë - de l'humaine fringale de «nouveautez » ou «nouvelles » (une quinzaine d'occurrences; cf. l'éd. de Trevor T. Peach dans BHR, LII-1, 1990, p. 109-121). Voir en amont la satire rabelaisienne du «pauvre monde [abusé] curieux de sçavoir choses nouvelles», dans la Pantagrueline Prognostication de 1533 (Euvres complètes, éd. M. Huchon, Paris, Gallimard, La Pléiade, 1994, p. 923-924).

36. Au début de son Apotheosis Capnionis (1522), la soif ou le refus de nouvelles traduisent justement ceux du Nouveau Testament. Voir l'éd. de Claude Blum et alii, Érasme, Laffont (« Bouquins »), 1992, p. 266 sq.

37. Irénée de Lyon, Contre les hérésies, Iv, 34, 1, trad. A. Rousseau, Paris, Le Cerf, 1984 ; nous soulignons. Voir bien sûr 2 Co 5, 17 ; Ap 21, 1 sq. (5 : «Voicy, je fay toutes choses neufves »), etc. On sait que cette prétention fut régulièrement jugée coupable ou mensongère par les païens : Sébastien Morlet, Christianisme et philosophie. Les premières confrontations ( $I^{e r}-V^{e}$ siècle), Paris, Livre de poche, 2014, p. 54-55, 81, etc. ; Michel Fédou, Christianisme et religions païennes dans le «Contre Celse » d'Origène, Paris, Beauchesne, 1988, p. 504-514. Rappelons que Lucien, très prisé de Des Périers, définit dans son De morte Peregrini $(\S 11)$ le

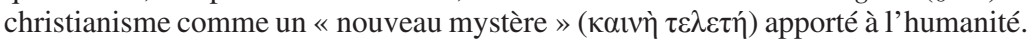
Il est loisible encore de voir dans la pierre philosophale " brisée nouvellement » par Mercure au second dialogue du $C M$ une allusion à la doctrine chrétienne (Nurse 17, Gauna 73). 


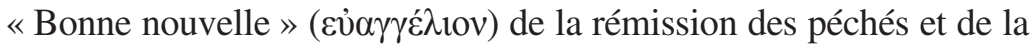
vie éternelle, autrement dit un masque du Christ.

Il importe à cet égard de préciser que Des Périers n'innovait pas entièrement. Non seulement la comparaison du Christ avec Mercure, naturellement sollicitée par leur commune condition de «fils de Dieu » médiateurs entre le Ciel et la Terre, n'était pas neuve (elle est déjà chez Justin), mais elle était dans l'air paganisant du temps. Il est vrai qu'elle pouvait encore faire scandale au siècle précédent ; ainsi, dans son Fortalitium fidei contra Judeos, Saracenos et alios Christianae fidei inimicos (1458), Alphonse de Spina décrivait-il, indigné, un livre sectaire hébreu suivant lequel «Jesus Christus habuerat spiritum Mercurii » (il évoquait une influence astrale) ${ }^{38}$. Mais moins d'un siècle plus tard, le tabou sera sérieusement ébréché. La vogue des Lettres gréco-latines et du « cicéronisme » y inclinait évidemment et - Rabelais s'en amusera - même les poètes néolatins parmi les plus dévots ne se feront plus scrupule d'appeler Dieu Optimus Maximus ou carrément Juppiter, avalisant de la sorte la comparaison de son Fils à Mercure ${ }^{39}$.

Sans doute celle-ci restait-elle plus rare que celle-là, car il était plus délicat de profaner allégoriquement la figure centrale de la religion que celle, plus lointaine et abstraite, de Dieu le Père. Cependant dès 1515, dans l'épilogue de son De Asse et vingt ans plus tard dans son De Transitu Hellenismi ad Christianismum (1535), où il dénonce pourtant la «contagion helléniste» de ses contemporains, le très catholique Guillaume Budé s'employait à donner une justification chrétienne de la comparaison qui nous intéresse :

[Dieu] s'est servi de son fils unique même et du premier-né de tout l'univers, comme d'un Mercure porteur de ses nouvelles, descendu du ciel pour examiner et organiser les choses humaines, revêtu de la puissance et du pouvoir suprême [...]. Le Fils sera comme un certain Mercure et médiateur de la vie céleste et éternelle ${ }^{40}$.

38. Voir notre article (avec Jean Letrouit), «Dieu et sa concurrence astrale », La Lettre clandestine, $\mathrm{n}^{\circ} 18,2010$, p. 269-292, ici p. 289 (voir aussi p. 290, «accepit [...] Mercurius sermonem [Christianorum]», et p. 282). Le Fortalitium a connu une fortune manuscrite et imprimée considérable au $\mathrm{XV}^{\mathrm{e}}$ siècle, mais le chapitre concernant la secte juive incriminée ici a parfois été supprimé.

39. Voir sur ce point notre «Livre de Jupiter », art. cit., p. 339-340.

40. G. Budé, De Transitu hellenismi ad christianismum (1535), trad. Maurice Lebel, Sherbrooke, Éditions Paulines, 1973, p. 6 et 34 ( «le Fils sera comme un certain Mercure et interprète de la vie céleste et éternelle ») ; ou trad. Marie- 
Ce livre eut-il sur Des Périers toute l'influence que lui accorda naguère Jean Bohatec ${ }^{41}$ ? Il est permis d'en douter et tentant, pour le moins, de la mettre en balance avec une source idéologique tout opposée, que Lucien Febvre estimait pour sa part fondamentale : celle du Contra Celsum d'Origène, réfutation de Celse traduite en latin dès 1512. Celse parlait à plusieurs reprises de Jésus comme d'un «messager » et il le comparait même explicitement à Mercure, à la grande indignation du théologien :

Le poète comique, pour provoquer le rire au théâtre, écrit que Zeus à son réveil envoya Hermès aux Athéniens et aux Lacédémoniens. Et toi, ne crois-tu pas que le Fils de Dieu envoyé aux Juifs est une fiction plus dérisoire ${ }^{42}$ ?

Parue quelque dix ans avant le Cymbalum et attribuable à Louis de Berquin, «luthérien» brûlé le 16 avril 1529 sur la place Maubert à Paris, la petite satire allégorique du catholicisme intitulée La Farce des théologastres pourrait représenter une autre source de Des Périers. Comme le résume son dernier éditeur, Gustave Lanson, Mercure y représente l'auteur, mais aussi un symbole de la "sagesse », raison et intelligence, et surtout « un médiateur entre la divinité et les hommes » qui le rend « tout à la fois Bon Pasteur, messager de la Bonne Nouvelle, médecin des âmes et témoin de la Parole, visage de Paul et du Christ $»^{43}$.

Madeleine de La Garanderie et Daniel Franklin Penham: Paris, Les Belles Lettres, 1993, p. 16 et 42 ; "Mercurius est Christus », lisait-on déjà dans le De Asse [1514], Paris, Bade, 1532, p. CLXXXvv. Sur Mercure chez Budé, voir La Garanderie, Christianisme et lettres profanes (1515-1535). Essai sur les mentalités dans les milieux intellectuels parisiens et sur la pensée de Guillaume Budé, Lille, ANRT, et Paris, Champion, 1976, spéc. p. 115-120, 163-164, 173-175. Les mythes antiques comportant des esquisses symboliques de la vérité, Mercure permet « de méditer sur la figure du Christ » (La Garanderie et Penham, p. XXXv).

41. J. Bohatec, "Calvin et l'humanisme [2]», Revue historique, t. 185-1, 1939, p. 71-104, ici p. 88-89.

42. Origène, Contre Celse, en particulier vI, 78 ; éd. Marcel Borret, Paris, Les Belles Lettres, 5 vol., 1967-1976, ici t. III [1969], p. 375-377 ; voir la réponse d'Origène, qui se prolonge en VI, 79. L. Febvre soulignait l'importance de ce passage dans "Origène et Des Périers. L'énigme du "Cymbalum mundi" ", $B H R$, II, 1942, p. 7-131, ici p. 84 (voir aussi p. 76 sq. sur les éditions latines alors disponibles des Euvres d'Origène incluant le Contra Celsum).

43. La Farce des théologastres (ca. 1527), éd. G. Lanson, Genève, Droz, 1989, Introduction, p. 23-24. Pour Paul, voir Ac I4, 12 et ici-même, infra. 
Nous pourrions multiplier les exemples ${ }^{44}$, mais pour nous en tenir aux lectures possibles de Des Périers, nous sommes tenté de mentionner pour terminer Calvin en personne. Dans un ouvrage fameux auquel l'un et l'autre collaborèrent en 1534/1535, la Bible d'Olivétan (un parent de Calvin, justement), le réformateur rédigea une épître-préface au Nouveau Testament intitulée «A tous amateurs de Jesus Christ et de son Evangile». Or dans cet écrit qu'il est loisible de regarder comme son tout premier texte théologique, et que Des Périers fréquenta à coup sûr, Calvin ne cite pas Mercure, mais il appelle le Christ «filz du treshault», «Mediateur », " grand Ambassadeur du père envoyé ca bas pour faire le salut des humains $»^{45}$. Un lecteur des Anciens pouvait difficilement ne pas songer à Mercure.

Bien sûr, alors que chez les quelques prédécesseurs immédiats de Des Périers que nous avons croisés la comparaison de Mercure avec le Christ s'entendait dans un sens allégorique positif, lui l'entendra tout autrement: dans son Cymbalum mundi, il mettra en avant les aspects mythologiques du dieu polymorphe parmi les plus négatifs et les mieux accordés aux critiques païennes et juives du personnage du Christ, comme quoi celui-ci aurait été un menteur, un voleur, un fraudeur, un enjôleur, un plagiaire, un arrogant, un fauteur de troubles, un baratineur, un illusionniste, etc., et finalement un imposteur - ce qu'est effectivement le dieu dans l'Amphitryon de Plaute ${ }^{46}$. Pour clore ce chapitre touchant la

44. On en trouvera chez Lanson (ibid., p. 24-25); dans le collectif Mercure à la Renaissance, éd. M.-M. de La Garanderie, Paris, Société française des seiziémistes, 1987 (cf. p. 5, 16-17, 20, 45-49, 157-158); chez Ludwig Schrader, «Hermes in Humanismus : Mythologische Anmerkungen zu Alfonso de Valdés, Guillaume Budé und Bonaventure Des Périers », Klaus W. Hempfer et Enrico Straub (dir.), Italien und die Romania in Humanismus und Renaissance [Mélanges Erich Loos], Wiesbaden, Steiner, 1983, p. 229-245.

45. Calvin, «A tous amateurs de Jesus Christ et de son Evangile», La Bible qui est toute la Saincte escripture. En laquelle sont contenus le Vieil Testament et le Nouveau, tranlatez en François. Le Vieil, de l'Ebrieu; et le Nouveau, du Grec, [Neuchâtel, Pierre de Wingle 1535], n. p.; rééd. Jacques Pannier : Paris, Fischbacher, 1929, p. 46, 45, 48 ; et dans Calvin, Euvres, éd. Francis Higman et Bernard Roussel, Paris, Gallimard (La Pléiade), 2009, p. 130, 129, 132.

46. Pièce justement alléguée dans le $C M$ III, Nurse 23 , Gauna 79 , à propos de Zeus, autre imposteur qui prend l'apparence d'Amphitryon « pour coucher avec Alcmena »; Mercure prend celle de Sosie chez Plaute. Nous avons développé ce sujet ailleurs et n'entendons pas y revenir : «Les visages du Christ dans le $C M$ », BHR, LXXv-3, 2003, p. 429-462. 
«nouveauté » mercurienne, nous nous bornerons à un détail qui nous semble définitivement confirmer que le dieu est, sinon toujours (l'univocité référentielle n'est pas de mise en pareille matière), du moins substantiellement, un masque du Christ. Il concerne la mission précise que Jupiter confie à son fils.

Songeons donc que le dieu de la communication, dieu qui traditionnellement relie les mondes ou les êtres, est commissionné par son père pour faire relier «tout à neuf » et «à la mode qui court» un livre qui tombe «tout en pieces de vieillesse $»^{47}$. Mercure ne sait trop si son commanditaire désire des ais de bois ou de carton, une couverture de veau ou de velours et des dorures, en changeant ainsi « la façon des fers et des clous, pour le faire à la mode qui court ${ }^{48}$. Il se demande aussi si c'est «à Athenes, en Germanie, à Venise ou à Romme » que l'on « relie le myeulx $»^{49}$. C'est finalement à Athènes, comprenons à Lyon, alors capitale de l'imprimerie française, qu'il atterrira ${ }^{50}$.

Mercure est certes un peu le dieu à tout faire du panthéon grécoromain, mais Des Périers insiste tant et si bien sur cette reliure que la chose intrigue. Il paraît en fait difficile de ne pas voir dans la mission de relier (religare) pour laquelle le dieu est spécialement dépêché sur Terre, une allusion à la nouvelle alliance (de alligare, attacher) que la venue du Christ vient sceller entre Dieu et les hommes, en remplacement de l'alliance ancienne, devenue obsolète et autant dire démodée, conclue autrefois avec le peuple d'Israël ${ }^{51}$. Si la Bible d'Olivétan (1535), à l'édition intellectuelle de laquelle Des Périers a participé, préfère rendre l'hébreu ברית (berith), ou le

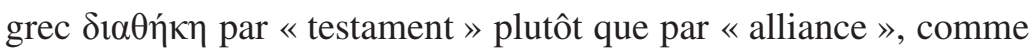
autrefois Jérôme (testamentum, plus rarement foedus, pactum), le

47. $C M$ I, Nurse 5 et 8 , Gauna 59 et 62 .

48. $C M$ I, Nurse 5, Gauna 59. Philippe Desan a apporté quelques éclaircissements historiques et techniques : « La reliure du livre de Jupiter : lecture bibliologique du $C M »$, Le Cymbalum mundi, éd. Giacone, p. 57-64.

49. Ibid. Lucien évoque souvent le surmenage des dieux, celui d'Hermès en particulier, dans les Dialogues des morts, XXIV.

50. L. Febvre, «Origène et Des Périers », p. 65 ; A. Mothu, «Les visages du Christ dans le $C M »$, art. cit., p. 429-462, ici p. 431 et n. 10.

51. Renvoyons, pour faire bref, aux références testamentaires données dans le Vocabulaire de théologie biblique de Xavier Léon-Dufour et alii, Paris, Le Cerf, 1962, s.v. «Alliance » (Jean Giblet et Pierre Grelot), et « Nouveau » (Ignace de la Potterie). « Nouvelle alliance » ou « Nouveau Testament » traduisent, comme l'on sait, Kaıv̀े $\Delta$ เ $\theta \dot{\prime} \kappa \eta$ (voir Lc 22, 20 ; 1 Cor 11, 25). 
mot n'était pas moins commun et Calvin lui-même l'employait dans sa préface au Nouveau Testament précédemment citée. Ce passage a d'ailleurs pu inspirer Des Périers :

Parquoy [C'est pourquoi] pour approcher les hommes de Dieu, tant Juifz que gentilz il estoit mestier [nécessaire] que une nouvelle alliance feust faicte, certaine, asseurée, et inviolable. Et pour icelle establir et confirmer, estoit besoing d'ung mediateur, qui intercedast et se interposast entre les deux parties pour les accorder $[\ldots]^{52}$.

Au reste, Calvin ne souligne-t-il pas aussi que Jésus, héraut de la «Bonne nouvelle et joyeuse » dont le Nouveau Testament porte la trace écrite, fut placé à la droite de son Père afin de «reparer toutes choses au ciel et en la terre $\aleph^{53}$ ? Réparer, c'est précisément ce que vient faire le jovial dieu aux talaires ailées et caducée du premier dialogue.

Ajoutons enfin à titre hypothétique et parce que Des Périers était grand amateur de jongleries verbales et de langues mêlées, que le mot même de "révélation» (ou revelatio), pour qualifier toute divulgation divine faite à l'homme ${ }^{54}$, pouvait s'entendre non seulement dans le sens de dévoilement, mais aussi - en mêlant latin et français, où le préfixe re peut exprimer aussi bien un retour en arrière qu'une répétition - de re-voilement, velo signifiant couvrir, velum le voile ou la toile, velamen la couverture ou l'enveloppe, et velatio la prise de voile conventuelle, au moins chez Augustin. Ainsi entendu, le mot nous ramène au plus près de l'idée d'une vulgaire opération de restauration de livre.

Quoi qu'il en soit, la mission que Mercure est supposé accomplir avorte lamentablement, puisqu'il se fait dérober le Livre de Jupiter juste après son atterrissage, dans la première taverne venue - il faut préciser qu'il avait «grand soif » (sitio, s'était justement plaint le Christ en croix, entouré comme Mercure de deux larrons) ${ }^{55}$.

52. Calvin, «A tous amateurs de Jesus Christ...», éd. Pannier, p. 41 ; éd. Higman-Roussel, p. 127 (avec renvoi à Jr 31, 31 et Hé 8, 7-13).

53. Ibid., éd. Pannier p. 45-46; Higman-Roussel p. 130. Nous soulignons.

54. Et non peut-être déjà la Doctrine salutaire donnée d'en haut dans sa totalité - encore que les protestants nous semblent avoir contribué à promouvoir cette signification, ce que ne dit pas Laurent Sentis dans son «étrange histoire du mot révélation" (De l'utilité des vertus. Éthique et Alliance, Paris, Beauchesne, 2004, p. 207-209).

55. Jn 19, 28, et $C M$ I, Nurse 6, Gauna 60. Les deux compagnons de boisson de Mercure vont en effet se révéler de fieffés «vilains », de « dangereux maraudz », voleurs du Livre de Jupiter. Les premiers mots de Mercure semblent ainsi faire 
Puis l'histoire tourne à la farce, à la grande honte de Jupiter, imprévoyant face au vol de son livre et impuissant à le récupérer, ridiculisé dans un bouquin de substitution où sont narrées ses honteuses métamorphoses érotico-mythologiques, incapable désormais de prévoir s'il va pleuvoir ou neiger, etc. D'où il faut semblet-il conclure que la nouveauté que Mercure-Jésus était supposé apporter aux hommes n'est jamais advenue et que ce qui en tient lieu aujourd'hui, à savoir la religion chrétienne, n'est que fable ou farce - le style éminemment théâtral du Cymbalum mundi venant en quelque façon animer ce dernier constat.

Cette caustique récusation du christianisme, qui traverse le motif de la nouveauté, semble consonner avec certaines déclarations des chiens Hylactor et Pamphagus que l'on trouve au quatrième dialogue. Le premier observe que les hommes «se faschent voulentiers des choses presentes, accoustumees, familieres et certaines, et ayment tousjours mieulx les absentes, nouvelles, estrangeres et impossibles », et il entend bien tirer profit de ce travers ${ }^{56}$. Le second lui fait écho à l'extrême fin et comme en conclusion du libelle, mais plutôt pour se désoler de cet état de fait : son compère fera bien parler de lui, «tant sont les hommes curieux et devisans voluntiers des choses nouvelles et estangeres $\gg^{57}$. Ces choses nouvelles et étrangères pourraient bien désigner en particulier la « nouvelle » espérance chrétienne, et les déclarations canines réfléchir le vieux philosophème épicurien suivant lequel le désir de ce que l'on n'a pas - nourri par les vaines opinions ou les promesses surnaturalistes - est un puissant toxique pour notre être sensible en sa quête du bonheur ${ }^{58}$.

écho aux (presque) dernières paroles du Christ - lesquelles, notons-le, avaient déjà été l'objet de détournements parodiques, comme le rappelle L. Febvre dans Le Problème de l'incroyance..., p. 145 et 152.

56. $C M$ IV, Nurse 41, Gauna 95 (nous soulignons); « tant sont les humains curieux de nouveauté... », disait le même Hylactor au début du dialogue (Nurse 34 ; Gauna 90).

57. $C M$ Iv, Nurse 43, Gauna 98 (nous soulignons).

58. Pour une vue d'ensemble, on verra Jean Salem, Tel un dieu parmi les hommes. L'éthique d'Épicure, Paris, Vrin, 1989, le chapitre « Le temps du plaisir », en particulier p. $53 \mathrm{sq}$. Des Périers devait connaître au moins Cicéron, De finibus, I, XVIII, 60 sq. ; et peut-être Origène, Contra Celsum, III, 80 (éd. Borret, II, p. 179180), à propos des « vaines espérances » chrétiennes. 


\section{Le Verbe Mercurien}

Un autre chaînon remarquable apparentant Mercure et le Christ, dans la pensée de Des Périers comme d'ailleurs dans la tradition érudite antérieure, a trait au langage. Car si le Christ est le $\Lambda$ ó ${ }^{\circ} \varsigma_{\text {de }}$ Dieu, le Verbe éternel et incarné de qui dérive toute manifestation de la parole divine dans la Création ${ }^{59}$, Hermès/Mercure est de son côté $\Lambda$ óyıs par excellence, le dieu du langage et de l'éloquence. Platon l'avait souligné dans son Cratyle $(407 \mathrm{e}-408 \mathrm{a})$ : à considérer les activités «d'interprète ( $\dot{\varepsilon} \rho \eta \eta v \varepsilon u ́)$, de messager, d'adroit voleur, de trompeur en paroles et d'habile marchand » du dieu, «c'est au pouvoir du discours » que tous se rattachent, jugeait Socrate, avant

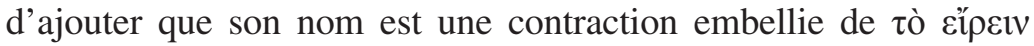
$\dot{\varepsilon} \mu \eta ́ \sigma \alpha \tau$, celui qui imagina ou machina la parole $(409 \mathrm{a}-\mathrm{b})^{60}$. On sait la fortune considérable que connut cette étymologie : c'est sous cet angle langagier, comme logius, que le dieu de la communication fut principalement décrit et son nom symboliquement analysé au Moyen Âge et à la Renaissance, où il put même être regardé par certains comme un patron ou un « signe du discours humaniste $»^{61}$, quand d'autres auteurs, plus sensibles aux aspects artificieux et captieux du langage dégagés par l'étymologie platonicienne, reconnaîtront plus volontiers dans le dieu «ce voleur de vaches, menteur, expert, dès sa naissance, en faux serments, dont l'Hymne homérique détaillait complaisamment les astuces $»^{62}$.

59. Dogme qui s'appuie, comme chacun sait, sur l'évangile de Jean (Jn 1, 1-14; cf. aussi 1 Jn 1, 1 et Ap 19, 13).

60. Nous suivons la traduction de Louis Méridier: Paris, Les Belles Lettres (CUF), 1931. L'adage « Mercurius supervenit» (Érasme, $n^{\circ} 3391$ Saladin) nous renvoie bien à cette invention du langage par Mercure : « On disait habituellement ces mots quand un silence venait à s'installer au milieu d'une réunion rassemblant de nombreuses personnes. On voulait dire par là qu'il n'est pas permis de parler en présence de Mercure, puisque c'est lui qui est l'inventeur de la parole ».

61. M.-M. de La Garanderie, «Le nom de Mercure, signe du discours humaniste », Mercure à la Renaissance, p. 15-17 (avec la discussion p. 157-160, et p. 167). Voir par ex. Isidore de Séville, dont les Etymologia connaissent plus de dix éditions entre 1470 et 1530 (cf. 45 sq. « Mercurium sermonem interpretantur... »), ou les très fameuses Illustrations de Gaule et singularitez de Troye (1510-1513) de Jean Lemaire de Belges (voir I, 35 : «Mercure signifie la parole, par laquelle toute doctrine est adressee et insinuee à nostre entendement »). Sans oublier les études citées supra (n. 40, 44) sur Mercure à la Renaissance.

62. Claudie Balavoine, "L'emblématisation de Mercure à la Renaissance », Mercure à la Renaissance, p. 55-67, ici p. 57. Non seulement le discours sert aux adroits voleurs, trompeurs ou marchands, mais son invention même semble 
Aussi la Vulgate, en traduisant par Verbum le Logos du début du prologue johannique (Érasme corrigera: Sermo, la parole discursive, et Olivétan traduira bien : « la parolle»), et adoptant de la sorte sans réserve la signification de logos comme oratio plutôt que ratio (choix lourd de conséquences pour la théologie chrétienne), jeta-t-elle immédiatement comme un pont invisible entre le dieu grec du langage et la Parole chrétienne. Un pont d'ailleurs point si discret que cela, si l'on prête attention au fait que l'unique mention d'Hermès/Mercure faite dans les Écritures vient amarrer sa figure à celle de Paul de Tarse, sous le rapport du langage précisément: nous lisons dans les Actes des apôtres $(14,12)$ que quand celui-ci prêchait avec Barnabé à Lystre, en Lycaonie (aujourd'hui en Turquie), et y réalisa le miracle de guérir un paralytique au moyen de ses discours et injonctions, il fut comparé par le peuple à Mercure «quoniam ipse erat dux verbi », «pource qu'il estoit porteur de la parolle» (trad. Olivétan) ${ }^{63}$. Quelque temps plus tard, sur l'agora d'Athènes, des philosophes épicuriens et stoïciens le compareront plutôt à une jacasse ou à une pie bavarde... ${ }^{64}$.

Le traitement que Des Périers réserve au langage de Mercure n'est pas moins cinglant, car c'est une parole substantiellement vide, ou bien captieuse (et moqueuse), que porte le messager des dieux du Cymbalum mundi, en particulier au deuxième dialogue. Or, une nouvelle fois, il ne fait guère de doute que sous le pétase ailé qui lui sert de couvre-chef, ce soit le Christ qui se profile. Nous apprenons en effet que, dans un passé indéfini, presque mythique quoique nouveau ${ }^{65}$, il s'était amusé à faire croire à trois « veaulx

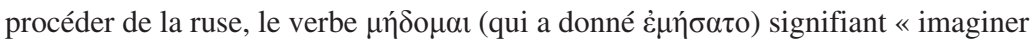
avec adresse », « machiner », « tramer ».

63. «Et vocabant Barnabam Jovem, Paulum vero Mercurium : quoniam ipse

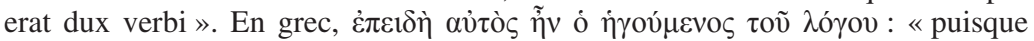
c'était lui qui avait la parole » (Bible de Jérusalem), « parce que c'était lui le porteparole » (TOB). Barnabé, qui accompagne Paul, est quant à lui comparé à Zeus, puisqu'il est le représentant officiel de l'Église à Antioche et au cours de leur mission commune en Asie mineure.

64. Ac 17, 18. Il est comparé à un $\sigma \pi \varepsilon \rho \mu o \lambda$ óyos. Le terme désignait un oiseau picoreur (le freux), le sens étant celui d' "oiseau bavard» (TOB, qui traduit « jacasse »), de « discoureur qui répète "comme un perroquet" des lieux communs » (Bible de Jérusalem, trad. « perroquet»). Olivétan traduit : «semeur de parolles ».

65. Voir supra, n. 37, sur la pierre «brisée nouvellement » par Mercure. 
de philosophes » ayant pour noms Cubercus (Bucer), Rhetulus (Luther) et Drarig («Girard "Érasme ou Roussel ?) ${ }^{66}$, qu'il avait broyé la pierre philosophale dans une arène sablonneuse, où maintenant ces imbéciles s'escriment «comme les enfans » à en retrouver des fragments, non sans se chamailler dès que l'un croit tomber sur la «feve du gasteau», comme dit Rhetulus ${ }^{67}$. Ils sont même "plus enfants que les enfants mesmes", ces vieillards «en perpetuelle enfance », or le royaume des Cieux n'est-il pas promis aux «petits enfants » dans les Évangiles ${ }^{68}$ ? Plus précisément, Mercure leur a fait croire que le moindre éclat de cette pierre leur permettrait de réaliser de surprenants miracles, comme d'enfoncer des portes ouvertes, guérir les bien-portants, parler la langue des oiseaux, etc. (écho parodique des promesses de Jésus à ses apôtres ${ }^{69}$. Très clairement, les trois alchimistes désignent des chercheurs de la Parole véritable du Christ déposée dans le Nouveau Testament (une fois celui-ci rendu par la philologie à sa vérité primitive), cette Parole étant en même temps, bien sûr, la pierre sur laquelle se doit bâtir et perpétuer l'Église du Christ (Mt I6, 18). Nos trois «philosophes », alchimistes et chrétiens à la fois ${ }^{70}$, sont donc tout bonnement à la recherche de la Philosophia Christi, pour reprendre la formule patristique remise à la mode par Érasme. D'ailleurs l'un d'eux, Rhetulus-Luther, le plus fort en

66. La question est débattue. Érasme (décédé en 1536) se disait fils d'un certain Girardus et la chose se savait; le prédicateur Roussel, disciple de Lefèvre d'Étaples, fut célèbre en son temps et aumônier de Marguerite de Navarre, que servait également Des Périers. Nous penchons pour Érasme mais l'ambiguïté est peut-être délibérée. Notons par ailleurs que « veau » (lourdaud, imbécile) était une insulte très prisée de Marot.

67. $C M$ II, Nurse 20, Gauna 76. Leurs puériles chamailleries : resp. Nurse 15-16 et Gauna 71-72; «Fiez vous à votre philosophie ; vantez vous d'avoir trouvé la feve au gasteau, à voir ce tintammare de tant de cervelles philosophiques », écrira Montaigne (Essais, II, 12 ; Villey p. 516).

68. Voir Mc 10, 14-15; Mt 18, 2-6; etc.

69. $C M$ II, Nurse 12, Gauna 67. Jésus promet à ses disciples qu'ils sauront soumettre les démons, parler des langues nouvelles, être immunisé contre les poisons, guérir les malades. Voir Mc 16, 17-20 ; cf. 6, 13 et Lc 10, 17 sq. La «petite piece» de pierre philosophale fait bien sûr penser au grain de sénevé de Mt 17, 20 ou Lc 17, 6; on la retrouve plus loin (Nurse 19; Gauna 75) quand Mercure explique à Luther sa haute valeur curative : allusion transparente à la foi qui guérit (et sauve).

70. La prétention du christianisme à incarner la «vera philosophia » remonte au moins à l'apologie de Justin. 
gueule des trois, n'hésite pas à pasticher la parole d'évangile, «Ils font très bien de chercher, car ce qui n'est trouvé se trouvera $»^{71}$.

Or, nous l'apprenons dès les premières lignes du dialogue, Mercure est un «abuseur », un trompeur, et un «caut varlet », un être bas, malin et sans scrupule ${ }^{72}$. De fait, la pierre philosophale n'a jamais existé, elle n'est qu'un leurre pour nigauds ; cela, le dieu, rendu méconnaissable par sa métamorphose en un vieillard vénérable, l'avoue personnellement aux trois nigauds :

O povres gens, vous fiez vous en Mercure, le grand aucteur de tous abuz et tromperie? Scavez vous pas bien qu'il n'a que le bec, et que par ses belles raisons et persuasions il vous feroit bien entendre de vessies que sont lanternes, et de nuées que sont poilles d'arain? Ne doubtez vous point qu'il ne vous ait baillé quelque aultre pierre des champs, ou, peult estre, de l'areine mesmes, et puis qu'il vous ayt faict à croire que c'est la pierre philosophale, pour se mocquer de vous, et prendre son passetemps des labeurs, coleres et debatz qu'il vous voit avoir en cuydant trouver la chose laquelle n'est point ? ${ }^{73}$

De mémoire d'homme, connut-on jamais «plus beau passetemps » et «plus joyeuse risee » que cette imposture ? Trigabus n'en connaît pas $^{74}$. Il est de même loisible de se demander s'il exista jamais blasphème à l'épice plus intense que celui réduisant le Verbe fait chair à n'avoir «que le bec », comme nous venons de le lire dans la bouche de son double mercurien.

Dans ce même second dialogue, le dieu latin a même fait croire à un admirateur, le triple railleur Trigabus, qu'il lui apprendrait bientôt la formule pour transformer sa « trongne » en la forme qu'il voudra, comme lui l'a fait en se muant en vieillard. Espoir déçu pour l'apprenti apôtre, qui n'entend rien au moment où Mercure se penche enfin à son oreille pour lui révéler son merveilleux secret ${ }^{75}$. Mais sur ce point au moins, on peut admettre que le dieu n'a pas

71. $C M$ II, Nurse 19, Gauna 75, faisant écho au Quaerite et invenietis de Mt 7, 7 ou Lc 11, 9. Les pastiches de paroles christiques sont nombreux dans le $C M$ et l'on en trouve même au quatrième dialogue, où Mercure est absent : ainsi le chien Hylactor s'exclame-t-il, «Qui me pourra prendre, si me prenne!» (Nurse 36, Gauna 91), faisant écho au Qui potest capere capiat de Mt 19, 12, tout en jouant sur le double sens de capio (ou saisir : attraper et comprendre). Rabelais avait en cela précédé Des Périers dans Pantagruel, chap. XVI (1532) ou XXVI (1542), p. 307 dans l'éd. Huchon de La Pléiade, 1994.

72. $C M$ I, Nurse 13, Gauna 67.

73. $C M$ II, Nurse 18-19, Gauna 74.

74. $C M$ II, Nurse 14, Gauna 69.

75. $C M$ II, Nurse 14-15, puis 21 , Gauna 70 et 77 . 
entièrement menti : ne soufflant mot à son disciple, il lui signifie tout bonnement qu'il n'y a rien à dire, que sa parole est vide. Elle n'est que du vent : "voilà toute la recepte », tout le secret est là. En définitive, les trois minables alchimistes de l'arène sont encore les mieux «tenuz » à lui et ses meilleurs disciples ${ }^{76}$, puisqu'ils ont beau désirer comme Trigabus $«$ cela qui n'est point $»^{77}$, ils ont saisi d'instinct le secret pour berner le monde : «payé[s] de paroles» par le dieu, ils ont hérité de son «grand babil et hault caquet» et à leur tour «contentent» ou payent maintenant leurs semblables de $«$ belle pure parolle $»^{78}$. Ainsi en va-t-il sans doute du message chrétien, pour Des Périers : si fallacieux qu'il soit, et peut-être justement parce que le vide produit souvent une forte résonance (comme font des cymbales), il sert aux habiles à subjuguer leurs congénères.

À les subjuguer, disons-nous, et bien sûr à les léser, les opprimer, voire les broyer. Sans entrer dans les détails, signalons que quand Mercure, en bon dieu magicien (comme fut Jésus au dire persistant de ses contempteurs juifs et païens, maintes fois démentis par les Pères et les apologistes) et pour faire parade de "nouveauté », entreprend au troisième dialogue de faire parler un pauvre cheval de labour, l'opération n'aboutit nullement à l'élévation du faible animal, telle que prévue dans le Magnificat, mais à augmenter sa persécution : la parole donnée par Mercure, la parole chrétienne n'apporte décidément rien de bon aux humbles, elle ne sert qu'aux maitres ${ }^{79}$. Telle serait donc peut-être la morale amère de la «parabole du cheval parlant», sur le fond acerbe dénonciation de la justification chrétienne - notamment paulinienne - de

76. CM II, Nurse 21, Gauna 77 (« Ilz sont grandement tenuz à toy, Mercure », observe Trigabus).

77. « Or je reviens à moy-mesmes et cognois que l'homme est bien fol, lequel s'attend avoir quelque cas de cela qui n'est point, et plus malheureux celuy qui espere chose impossible » : telle est la conclusion toute épicurienne du second dialogue, telle que la tire Trigabus ( $C M$ II, Nurse 22, Gauna 77).

78. $C M$ II, Nurse 20, Gauna 76 ; le topos des «trois imposteurs » affleure assez nettement. "Contenter» est encore payer au XVI ${ }^{\mathrm{e}}$ siècle (cf. Huguet). Au premier dialogue, l'hôtesse qui ne pouvait croire que Mercure pourrait allonger sa vie en parfaite santé (ersatz de la vie éternelle), refusait qu'il la «paye de si riches promesses » (CM I, Nurse 10, Gauna 64).

79. $C M$ III, Nurse 30-33, Gauna 85-88. Nous avons commenté ce passage, notamment, dans «Sur le chemin de Dabas. Trois notes sur le $C M », B H R$, LXXVII-2, 2015, p. 399-409, ici p. 403-406 : «Phlégon ou l'élévation manquée ». 
l'ordre social tel que voulu par Dieu, puis de la servitude et de la persécution imposées en son nom à la multitude animalisée du petit peuple. Il n'y a pas si longtemps, Luther n'appelait-il pas sous le même prétexte sacré au massacre des paysans en révolte, comparés par lui à l'âne « qui veut recevoir des coups $»^{80}$ ?

La satire de la Révélation chrétienne trouve un ultime prolongement vers la fin du quatrième dialogue, quand un autre animal parlant, le chien Hylactor, propose de conter à son congénère Pamphagus - qui les sait déjà par cœur - « plusieurs belles fables » (et une chanson) qu'il a « ouy racompter autrefoys ». Ce sont alors autant de mythes proprement chrétiens qui apparaissent, à peine camouflés, sous l'écaille païenne: celui de «Prometheus», ce bienfaiteur de l'humanité mis en croix sur le Caucase par ordre de Zeus ; celui du «grand Hercules de Libye», légendaire « Chassemal et Sauveur», comme dira Ronsard; celui du jugement de Pâris, dont la pomme de discorde fit jadis choir l'humanité dans le chaos ; celui de " $[\mathrm{P}]$ saphon », dont des oiseaux annoncèrent la divinité ; celui d' «Erus qui revesquit » après son décès ; et enfin, pour couronner le tout, «la chanson de Ricochet», rythmée de promesses dont on ne voit jamais le terme ${ }^{81}$. Inutile de préciser que pour évoquer toutes ces fadaises, les chiens ont pris grand soin de se dissimuler dans un « petit boscage ».

Comment ne pas songer à ce que Calvin ou Henri Estienne - l'un et l'autre citant nommément Des Périers - diront bientôt de ces furieux «mocqueurs » de Dieu, ces chiens imbus de Lucien et Lucrèce, pour qui la Bible vaut la fable, qui estiment que «toutes religions ont esté forgées au cerveau des hommes », et encore que l'espérance chrétienne n'est que «pour amuser les idiots » et ses menaces "pour espovanter les petis enfans », etc. ${ }^{82}$; bref, que

80. « Der Esel will Schlage haben und der Pöbel will mit Gewalt regiert sein. Das wusste Gott wohl. Darum gab er der Obrigkeit nicht einen Fuchsschwanz, sondern ein Schwert in die Hand » (Ein Sendbrief von dem harten Büchlein wider die Bauern, 1525, dans Martin Luthers Werke, Weimar, Hermann Böhlaus, XVIII, 1908, p. 394). Mélanchton précisera la même année qu'au cheval va le fouet, à l'âne la bride et au dos des paysans la trique (Hugues Neveux, Les Révoltes paysannes en Europe, XIV -XVII siècle, Paris, Albin Michel, 1997, p. 227-228).

81. $C M$ IV, Nurse 42-43, Gauna 97-98. Passage commenté par nous dans «Les fables canines du $C M », B H R$, LXXIV-2, 2012, p. 297-310.

82. Calvin, Des scandales (1550), éd. Olivier Fatio, Genève, Droz, 1984, p. 141-142 («Deperius » est nommé quelques lignes plus haut, p. 138); Estienne, Traité préparatif à l'Apologie pour Hérodote (1566), éd. Bénédicte Boudou, 
tout l'édifice religieux ne repose que sur de vaines «paroles » $(\text { verba })^{83}$ ?

«Pernicieux » était bien le terme approprié pour définir ce petit Cymbalum qui, sous sa «joyeuse et facétieuse » écorce farcesque, médisait si fort de la Bonne Nouvelle apportée par le Verbe fait Homme. L'interprétation dominante dans la seconde moitié du $\mathrm{XX}^{\mathrm{e}}$ siècle et jusqu'à nos jours, suivant laquelle son auteur - qu'on le baptisât évangéliste "hésuchiste», mystique proche des « libertins spirituels », ou catholique bon teint ${ }^{84}$ - n'avait pas rompu avec le christianisme, est en toute rigueur intenable. On n'use pas d'équivoques retorses et d'allusions biaisées aux Écritures quand on défend de si saintes causes, et il est au contraire probable que la «cymbale du monde» désigne au premier chef Jésus, dont la geste et le nom même ont produit tant de vain bruit en ce monde ${ }^{85}$. Cependant le préjugé suivant lequel nos ancêtres baignaient globalement dans la foi procède de mobiles affectifs et idéologiques parfois puissants (nostalgie d'un âge d'or de la foi attestant notre déclin civilisationnel, ou condescendance orgueilleuse vis-à-vis de ces aïeux trop crédules), de sorte qu'il n'est pas si facile à dissoudre,

Genève, Droz, 2007, I, p. 293-294 («Bonaventure des Periers » est cité p. 292). Nous citons Calvin - qui traite ici et ailleurs ses adversaires de « chiens ». Estienne le suit globalement, mais il étoffe notablement son réquisitoire.

83. Nous citons ici une lettre d'Antoine Fumée à Calvin de 1542 ou 1543, Correspondance des réformateurs dans les pays de langue française, éd. AiméLouis Herminjard, Genève-Bâle-Lyon, t. VIII, 1883, p. 233 : les achristes soutiennent que « religionem nostram nihil praeter verba habere [...] » (nous soulignons).

84. Ces opinions encore influentes ont été lancées respectivement par VerdunLouis Saulnier («Le sens du CM... », BHR, XIII-1 et 2, 1951, p. 43-69 et 137-171), Peter Hampshire Nurse (introd. à son éd. du $C M$, Manchester Univ. Press, 1957) et Michael Screech (préface à la rééd. de l'édition précédente, Genève, Droz, 1983). Une autre ligne de lecture aujourd'hui très en faveur, dont Jean-Claude Caron s'est fait l'historien au colloque de Rome sur le $C M$ (éd. F. Giacone, p. 299-313), affirme son irréductible opacité herméneutique et sa dimension avant tout littéraire et comique.

85. «Cymbalum mundi » est - suivant Pline (Hist. nat., préface) repris par Érasme (adage $n^{\circ} 3982$ Saladin) - le sobriquet que l'empereur Tibère décerna au vaniteux grammairien Apion, qui se flattait d'immortaliser ceux à qui il dédiait quelque ouvrage : en fait plutôt la tapageuse résonance d'un mauvais tambourin, corrige Pline. Il en irait ainsi de Jésus, cause du vaste tintamarre appelé christianisme. Il résonnait peut-être à l'unisson de la «trompette evangelicque Monseigneur sainct Paul» de Rabelais (Pantagrueline prognostication, 1532, 1535,1537 , etc). 
serait-il scientifiquement réfuté ${ }^{86}$. Un cas exemplaire pourrait-il le désagréger enfin? Personne n'en fera le pari car enfin, n'est-ce pas le même grand historien, Lucien Febvre, qui soutint en 1942 que le $\mathrm{XVI}^{\mathrm{e}}$ siècle était fondamentalement croyant et démontra la même année l'antichristianisme foncier du Cymbalum mundi - en suivant d'autres voies que les nôtres ${ }^{87}$ ? La parade de Febvre, ou disons son tour de force, consista à prétendre que l'ouvrage était en avance sur son temps : «un livre précurseur. Le livre d'un précurseur ${ }^{88}$. Mais qui croira aujourd'hui à ce subterfuge si commode ? Ajouté à ce que nous savons aujourd'hui de l'incroyance médiévale et prémoderne, le rejet très mûr et décomplexé du christianisme dont fait montre le Cymbalum nous oriente au contraire définitivement sur l'idée qu'il était profondément de son temps, au double sens où il en révélait une strate essentielle, nullement désynchronisée, mais obstinément refoulée, constamment enfouie et recouverte, car jugée inacceptable par les gérants laïcs et religieux de la doxa publique, par l'élite constituée de leurs vassaux et obligés, et partant par l'essentiel de la société visible - à nos yeux contemporains, s'entend.

alain.mothu@ paris-sorbonne.fr

86. Évidence psychologique que c'est une chose de se dire chrétien et une autre de croire ; évidence socio-historique et ethnographique que le «bain chrétien » était fissuré de mille parts ; évidence factuelle de cas innombrables d'ignorance crasse ou de franc rejet de toute notion religieuse, etc. Depuis un demi-siècle, des dizaines d'études sérieuses ont, sous des angles divers, pulvérisé la thèse défendue par Lucien Febvre en 1942 dans Le Problème de l'incroyance (voir, pour faire court, notre «Livre de Jupiter», p. 360, avec les références ad loc.). Même le dernier « postfacier» du livre (2003), Denis Crouzet, s'en désolidarise ; elle se survit néanmoins assez bien dans les études littéraires.

87. Le Problème de l'incroyance au XVI' siècle - où il n'est quasiment rien dit du $C M$ - parut à Paris, chez Albin Michel, et « Origène et Des Périers » chez Droz, également à Paris (Febvre estimait notamment que la lecture du Contra Celsum d'Origène par Des Périers fut déterminante ; or il est loin de l'avoir démontré). On peut songer à Simon de Tournai, Du Perron, Maldonat et d'autres, qui se seraient vantés de pouvoir démontrer, du jour au lendemain, l'existence de Dieu puis son inexistence...

88. «Origène et Des Périers », p. 131 (phrase conclusive du livre). Febvre postule une conversion soudaine de Des Périers en libertin «d'avant-garde » (p. 72, 125), causée par deux rencontres simultanées vers 1536 (p. 40 et passim) : celle d'Étienne Dolet, mal sentant de la foi, et celle des thèses de Celse préservées dans le Contra Celsum d'Origène. Cependant cette dernière rencontre est fort exagérée, sinon difficile à établir (Lucien fut en tout cas autrement plus influent que Celse !), et on ne sait strictement rien des relations de Des Périers avec Dolet (Febvre l'avoue p. 56). Parler d'une évolution brusque de Des Périers est encore très conjectural : on peut lire et travailler sur la Bible sans avoir la foi, pour gagner sa vie, et la Bible même (ses impossibilités, ses lacunes, ses contradictions) peut détourner de la Bible : Rome n'en a jamais douté. 


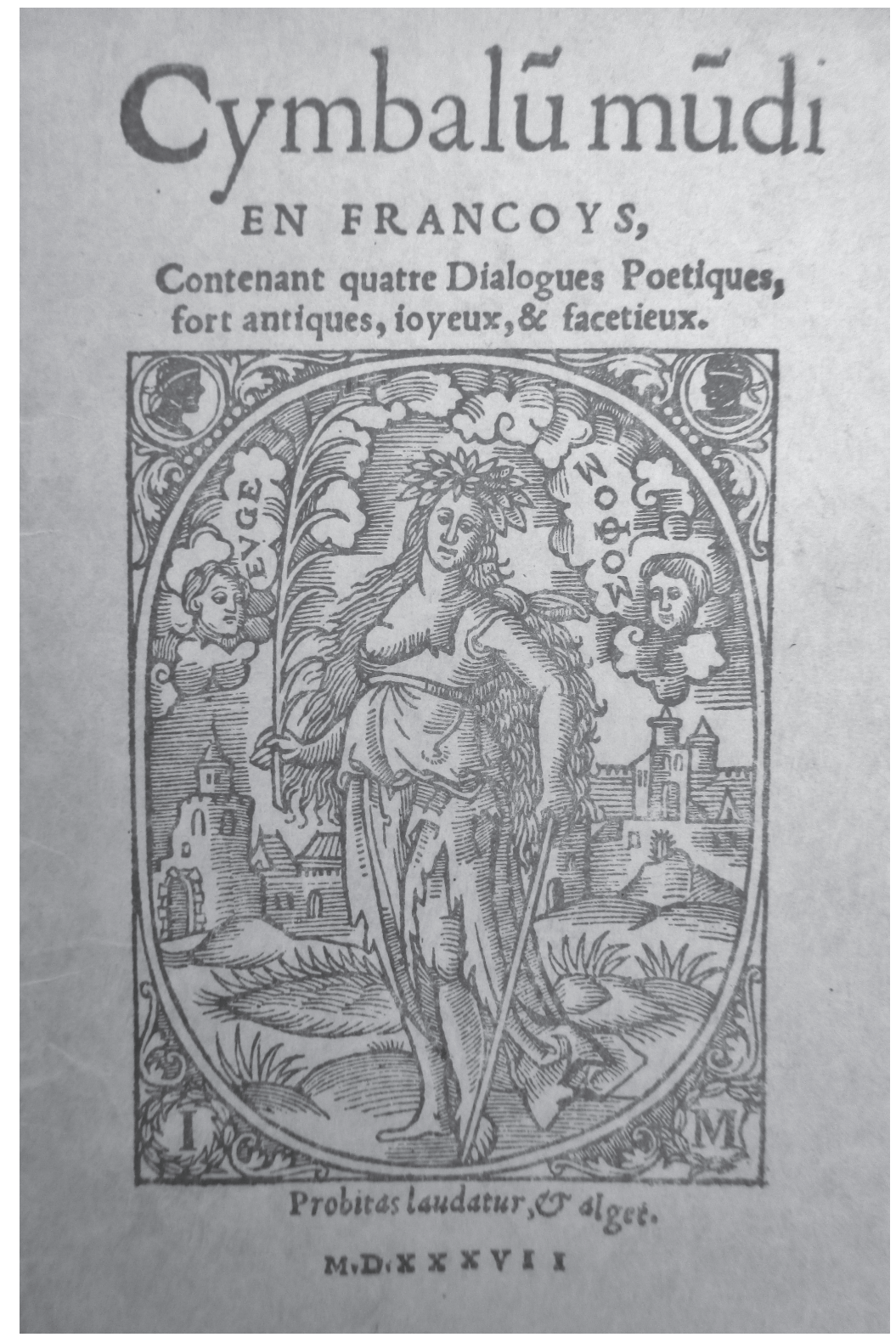

